\title{
A Comparison Study of Students' Performance in Pre and Post Result of A Mathematics Competency Test
}

\author{
Najiyah Safwa Khashi'ie ${ }^{1, a}$, Rahaini Mohd Said ${ }^{1}$, Nurul Amira Zainal ${ }^{1}$ and Nor Hamizah Miswan ${ }^{1}$ \\ ${ }^{1}$ Faculty of Engineering Technology, Universiti Teknikal Malaysia Melaka, Hang Tuah Jaya, 76100 Durian Tunggal, Melaka, \\ Malaysia
}

\begin{abstract}
The objective of this study was to compare the performance of Engineering Technology (ET) students' in a Pre and Post Mathematics Competency Test during their first year of study at the Faculty of Engineering Technology (FTK), Universiti Teknikal Malaysia Melaka (UTeM). This article also aims to examine the student's understanding in the area of Mathematics, particularly in Algebra, Trigonometry and Functions. A total of 176 first year students from the Department of Mechanical Engineering Technology (JTKM) were chosen to answer the Mathematics Competency Test. The pre-test was held in the first week of the semester, while the post-test was held during the second semester. The results showed that the students' performance in post-test was better compared to that pre-test. However, statistical analysis on students' performance by each question showed that most of the students did not understand the basic concepts in Algebra, Trigonometry and Functions.
\end{abstract}

\section{Introduction}

These days, it is important to increase the number and competency of students in science, technology, engineering and mathematics (STEM) for future career development. The Faculty of Engineering Technology (FTK), Universiti Teknikal Malaysia Melaka (UTeM) is one of the universities in the Malaysian Technical University Network (MTUN) which provide Engineering Technology Programs (ETP) [1]. This program is oriented towards applications whereby more practical and hands-on activities are assessed, and introductory mathematics courses, science courses and qualitative introductory to engineering fundamentals are provided. One of the important subjects that support and relates to ETP is mathematics [1,2]. The aims of this paper are to compare the performance of ET students while learning Mathematics in their first year of study at FTK, UTeM and examine their understanding in the area of Mathematics, particularly in the topics of Algebra, Trigonometry and Functions.

Students frequently encounter problems in learning mathematics involving calculations and understanding the concept and method used [2]. According to [3], factors affecting difficulties in learning and understanding Mathematics are psychological incidences like fear and lack of confidence, the curriculum of mathematics itself which fails to show much relevance in real life applications and the way academicians or mathematicians attract students to learn mathematics. It is believed that a good mathematical background is a prerequisite in understanding engineering concepts, especially for engineering and engineering technology students. The lack of understanding in basic mathematical principles can result in the inability to solve numerous subjects which require mathematics [4]. Furthermore, Mathematics has always been perceived as a difficult and demanding subject [5]. Difficulties in mathematics are often caused by lacking of mathematics skills [6]. The understanding of the knowledge, skills and commitment of teachers are keys to succeed in mathematics [7]. The preconceived notion that Mathematics is difficult might have affected the students' performance in mathematics. Coupled with this is the fact that mathematics anxiety is brought about by low self-esteem and the fear for failure. Perhaps these negative preoccupations have adversely affected the students' performance.

Academic performance is the ability to study and remember facts and the capability to communicate acquired knowledge verbally or on paper, both of which are commonly measured by means of grades [8]. Algebra, Trigonometry and Function are few examples of broad parts in mathematics. Although these topics are basics and fundamental, but they are important especially for ET students who will apply in other subjects such as Physics, Chemistry, Thermodynamics and Fluid Mechanics. According to a previous study by [8], students who took the Algebra and Trigonometry subjects for two academic years were not able to achieve the required criteria. Furthermore, studying technique was a common factor affecting the performance of the students in mathematics. A paper by [9] compared students' performance in a mathematics test and the circuit analysis course. The mathematics test consisted of several prerequisite topics in circuit analysis such as basic algebra, complex numbers, integral and differential calculus, and was held in the beginning and end of the semester. Results based on the mathematics and electric circuit tests were

\footnotetext{
${ }^{\mathrm{a}}$ Corresponding author: najiyah@utem.edu.my
} 
compared and showed that there were correlations between both subjects. In this study, Algebra Trigonometry and Function topics were chosen as the basis for research evaluation and assessment benchmark since these parts of mathematics are useful and relevant for engineers and technologists.

\section{Methodology}

This study was conducted to compare the performance of ET students while learning mathematics during the first year of study at FTK, UTeM. The pre-test for the Mathematics Competency test was held in the first week of the semester, while the post-test was held in the second semester. The Mathematics Competency Test consisted of 40 questions; 20 questions (No 1-20) focused on the topics of Algebra, Trigonometry, Solving Equation and Function, while 20 questions (21-40) focused on the topics of Derivation and Integration.

Data were collected from a total of 176 first year students from the Department of Mechanical Engineering Technology (JTKM) as samples for the entire population who took the competency test in the first year. A summary of students' demographics is shown in Table 1; 76 students were studying for Bachelor's Degree in Mechanical Engineering Technology (Automotive Technology), 38 students were studying for Bachelor's Degree in Mechanical Engineering Technology (Refrigeration and Air-Conditioning Systems) and 62 students were studying for Bachelor's Degree in Mechanical Engineering Technology (Maintenance Technology). Table 2 exhibits the contents description in the Mathematics Competency Test (Questions 1-20). There are $30 \%$ questions on Algebra and solving equation and 20\% questions on Trigonometric and Function.

Table 1. Total of First Year Students in Department of Mechanical Engineering Technology by Gender and Programs.

\begin{tabular}{|l|c|c|c|}
\hline \multirow{2}{*}{ Department } & \multicolumn{3}{|c|}{ Number of Students } \\
\cline { 2 - 4 } & Male & Female & Total \\
\hline $\begin{array}{l}\text { Bachelor's Degree in } \\
\text { Mechanical Engineering } \\
\text { Technology (Automotive } \\
\text { Technology) }\end{array}$ & 62 & 14 & 76 \\
\hline $\begin{array}{l}\text { Bachelor's Degree in } \\
\text { Mechanical Engineering } \\
\text { Technology (Refrigeration } \\
\text { and Air-Conditioning } \\
\text { Systems) }\end{array}$ & 30 & 8 & 38 \\
\hline $\begin{array}{l}\text { Bachelor's Degree in } \\
\text { Mechanical Engineering } \\
\text { Technology (Maintenance } \\
\text { Technology) }\end{array}$ & 52 & 10 & 62 \\
\hline
\end{tabular}

Table 2. Description of content in Mathematics Competency Test (Questions 1-20).

\begin{tabular}{|l|c|c|c|}
\hline \multicolumn{1}{|c|}{ Content } & Question No & $\begin{array}{c}\text { No. } \\
\text { of Item }\end{array}$ & Weightage \\
\hline $\begin{array}{l}\text { Algebraic } \\
\text { Expression }\end{array}$ & $1,2,3,4,5,11$ & 6 & 30 \\
\hline Trigonometry & $13,14,15,16$ & 4 & 20 \\
\hline Solving Equation & $6,7,8,9,10,12$ & 6 & 30 \\
\hline $\begin{array}{l}\text { Function and } \\
\text { Domain }\end{array}$ & $17,18,19,20$ & 4 & 20 \\
\hline
\end{tabular}

\section{Results And Discussion}

\subsection{Overall Result}

Figure 1 shows a comparison of students' performance in the Pre and Post Competency Test (Question 1-20) by program in JTKM. Result show that there was only a slight increment between the pre- and post-tests whereby less than $50 \%$ of students could understand and answer the questions correctly.

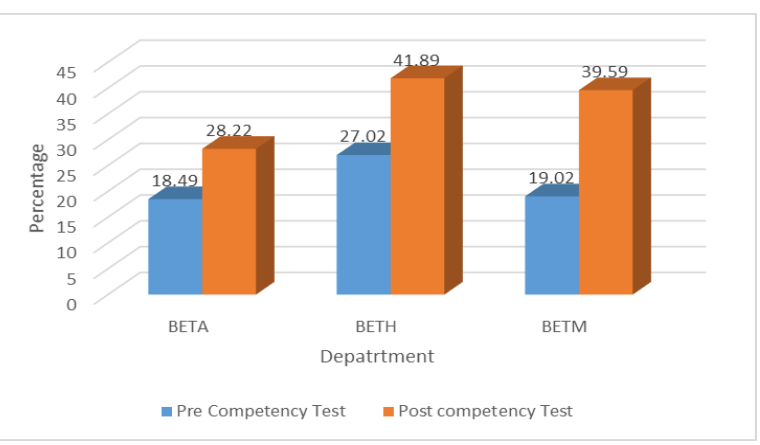

Figure 1. Students' performance in the Pre and Post Competency Test (Question 1-20) by program in JTKM

Figure 2 illustrates the percentage of JTKM students' performance for pre and post competency test by question and content. The graph shows changes in the percentage of students' obtaining correct answers between the preand post-tests. The graph also shows that more than $40 \%$ of students understood and correctly answered Question 1 (algebraic expression), Question 7 (solving equation), Question 10 (solving equation) and Question 14 (trigonometry), while less than $10 \%$ correctly answered Question 6 (solving equation), Question 19 (function and domain) and Question 20 (function and domain). Based on this graph, it can be seen that students had lack of understanding and knowledge in the topics of algebraic expression, trigonometry, solving equation and function since the percentage of students who were able to answer the question correctly was low. There were many factors affecting these results, such as the different backgrounds of study before entering FTK and psychological incidences like mathematics anxiety. 


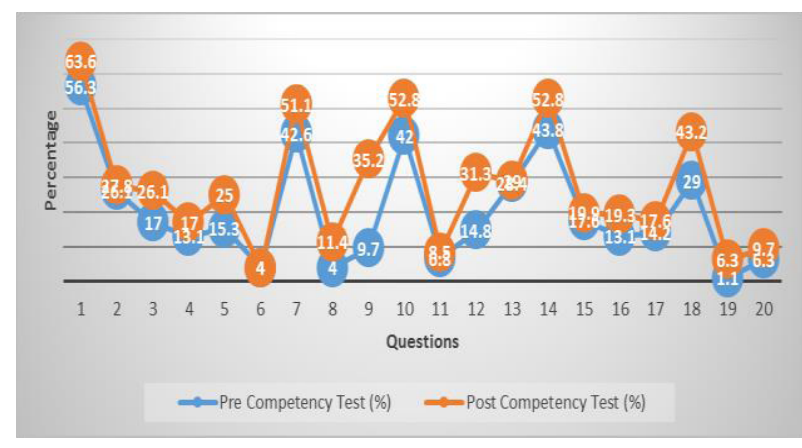

Figure 2. Percentage of JTKM students' performance for preand post- competency test by question and content

Table 3. Paired Samples Statistics : Means.

\begin{tabular}{|c|c|c|c|}
\hline & Mean & $\begin{array}{c}\text { Number of } \\
\text { samples }\end{array}$ & $\begin{array}{c}\text { Standard } \\
\text { Deviation }\end{array}$ \\
\hline Pre-Test & 4.05 & 176 & 3.243 \\
\hline Post-Test & 6.94 & 176 & 3.607 \\
\hline
\end{tabular}

Table 4. Paired Samples Statistics : Correlation.

\begin{tabular}{|c|c|c|}
\hline & r & $\begin{array}{c}\text { Sig. } \\
\text { Value }\end{array}$ \\
\hline Pre-Test - Post-Test & 0.641 & 0.000 \\
\hline
\end{tabular}

From the results shown in Table 3, the mean for postcompetency test score was approximately higher by 7 than that of pre competency test, while the Pearson correlation between pre- and post-tests (Table 4) shows moderate and positive correlation with the value of $r=$ 0.641 , with a significant value of $\rho<0.05$. This indicates that the students' performance in post-test was better than pre-test after taking the Mathematics course in FTK for one semester.

\subsection{Analysis of Variance, ANOVA}

ANOVA is a statistical method used to test the significant difference among means. ANOVA is also a hypothesis test that consists of a null hypothesis $\left(\mathrm{H}_{0}\right)$ and an alternative hypothesis $\left(\mathrm{H}_{1}\right)$. If the $\rho$ value is greater than the critical value, which is 0.05 , then the null hypothesis $\left(\mathrm{H}_{0}\right)$ is rejected and the alternative hypothesis $\left(\mathrm{H}_{1}\right)$ is accepted. In this article, ANOVA is conducted at $95 \%$ confidence levels to test the significant difference in students' performance after taking the pre- and postcompetency test. ANOVA is employed to test the following hypothesis:

$\mathrm{H}_{0}$ : There are no significant difference between pre competency test and post competency test.

$\mathrm{H}_{1}$ : There are significant difference between pre competency test and post competency test.

Table 5 below shows the critical value, $\rho$ less than 0.05 which was 0.000 . Thus the null hypothesis $\left(\mathrm{H}_{0}\right)$ is rejected, which also implies that there were significant differences between pre competency test and post competency test.
Table 5. Paired T-Test for Pre and Post Test

\begin{tabular}{|c|c|c|c|}
\hline & Mean & $\begin{array}{c}\text { Standard } \\
\text { Deviation }\end{array}$ & P value \\
\hline $\begin{array}{c}\text { Pre Test- } \\
\text { Post Test }\end{array}$ & 0.14 & 0.1460 & 0.000 \\
\hline
\end{tabular}

\section{Conclusion}

The focus of this study was to determine the relative relationship in student's achievement in Mathematics Competency Test between 'before' (early of semester) and 'after' (in second semester). There were four components in the test, which were Algebraic Expression, Solving Equation, Trigonometric Function and lastly Function and Domain. The results showsed there were slightly significant difference between 'pre' and 'post' tests. However still, the percentage of students getting the right answers was low.

For algebraic expression component, knowledge on factorization, indices and inequalities are really important to solve a problem. Based on the findings, we realized that students failed to express and simplify the given question in the simplest way. Students mostly repeated the same error in pre- and post-tests probably because they misunderstood algebraical concepts as mentioned above. The second component involved solving equations. The questions wanted the student to solve giving equation and to find the values (unknown) that fulfil a condition stated depending on the problem. The percentage of students getting right answer was still below than $50 \%$. Ultimately, the result was lower than the first touch component. However the percentage of getting the right answers was higher when comparing pre- and post- results for each question. This indicates that students were able to gain more conceptual understanding of mathematics by the end of the semester. This also shows that students are improving their skills and abilities in solving mathematics problems.

As for trigonometric questions, the results showed no significance different for each question, even though the percentage of the post- result was higher. To simplify this, there are two main reasons as to why this could happened. Firstly, students completely failed to understand the questions, and secondly, students did not use the trigonometric function very often in daily life. Therefore, lack of practise definitely could have led to poor skills or bad performance as shown in the findings. The last component was Function. Findings showed that more than half of the samples answered the questions incorrectly for this topic, both in pre- and post-tests. There are several reasons that could have triggered this event. For example, the inability to understand the relation between domain and range in a graph, as well as misunderstanding the basic concepts in Mathematics.

In a nutshell, engagement of preconceptions in Mathematics is important in order to understand and solve Mathematical problems. If this does not happened, students will not achieve the full comprehension of the new material related to the previous concepts. Worst, students may reject all new information or struggle to implement the wrong concepts, resulting in a 
misunderstanding of the contents. In conclusion, eliminating students' misconceptions is a crucial goal in this new era.

The authors would like to acknowledge Faculty of Engineering Technology and Universiti Teknikal Malaysia Melaka (UTeM) for financial support under the UTeM short term grant PJP/2015/FTK(15B)/S01427.

\section{References}

1. N. S. Khashi'ie, K. Hamzah, I. Waini, F. Salim, M. F. Mukhtar and N. A. Zainal. International Journal of Science and Research (IJSR) 3(10), 1017-1019 (2014)

2. K. Hamzah, N. S. Khashi'ie, N. H. Hussin, M. F. Wahid, C. W. M. Che Wan Mohd Zalani and S. K. Sayed Nordin, International Journal of Humanities and Social Science (IJHSSI) Volume 3 Issue 3, 2528 (2014)

3. A. Nordin, Prosiding Simposium Kebangsaan Sains dan Matematik ke V, Universiti Teknologi Malaysia, 20-22 (1992)

4. M. Bursal and L. Paznokas, School Science and Mathematics 106(4), 173-180 (2006)

5. M. H. Ashcraft and K. S. Ridley, Am. Psychol. Soc., 181-185 (2002)

6. S. F. Mokhtar, Z. M. Yusof and M. Misiran, Journal of Applied Sciences Research 8(8), 4133-4137 (2012)

7. V. Suthar, R. A. Tarmizi, H. Midi and M. B. Adam, Proceedings of the $4^{\text {th }}$ International Conference on Research and Education in Mathematics, 171-178 (2009)

8. B. L. Dinglasan and A. D. C. Patena, Alberta School Of Business, Research Paper No. 2013-1308 (2013)

9. J. Jalkio, ASEE Annu. Conf. Expo, 14.15.1-14.15.7 (2009) 